\title{
Measuring Health Outcome and Economic Cost associated with Childhood Acute Respiratory Infections: Case of Squatter Settlements in Kathmandu Valley
}

\author{
Arjun Bahadur Pathak* \\ Naveen Adhikari**
}

\begin{abstract}
Among the groups of Acute Respiratory Infections (ARIs), pneumonia accounts as the second cause of annual childhood deaths after diarrhea and this is even more serious among poor households and slum areas of Nepal. This study provides an estimate of the household cost associated with ARIs illness and burden of diseases in terms of Disability Adjusted Life Years (DALYs). The data for the analysis have been collected from the households of 15 squatter settlements in Kathmandu Valley. Relevant illness related information with recall period of one month and six months along with socio-economic characteristics of household and family members was collected from the survey. The findings suggest that among the households with affected children within the recall period, 71.66 percent tried some kind of treatment either at home or at health care providers'. The cost composition shows that 92.27 percent indirect cost, 4.77 percent direct cost and 2.96 percent averting cost to households due to childhood ARIs and when "Loss of earning due to premature death" component is not accounted, cost structure is 12.05 percent, 54.27 percent and 33.08 percent respectively. Total discounted years of 70.87 equivalent have been found lost with disability (time lived with sickness or time lost due to death) for under-five children in squatter settlements and yearly 100.05 Quality Adjusted Life Years (QALYS) have been gained due to various treatments-seeking behavior of households in the squatter settlements. Based on the study finding, it is recommended that to minimize total cost of childhood ARIs, households need to offer better averting activities and increase care-seeking behavior to their children.
\end{abstract}

Key words: acute respiratory infections, squatters in Kathmandu valley, children, disability adjusted life years, household cost

\section{INTRODUCTION}

Acute respiratory infections (ARIs), a group of diseases that includes pneumonia, influenza, and Respiratory Syncytial Virus (RSV), result in 4.25 million annual deaths worldwide (WLF, 2010). Pneumonia constitutes a major proportion of childhood

\footnotetext{
* Mr. Pathak is Lecturer of Economics at Golden Gate International College, Kathmandu.

${ }^{* *} \mathrm{Mr}$. Adhikari is Lecturer of Economics at Central Department of Economics, Tribhuvan University, Kirtipur, Nepal
} 
diseases responsible for estimated 1.4 million children under age of five years, accounting for about 20 percent of all children below five year deaths across the countries in the world (WHO, 2011). In South Asia, 21 percent of under five mortality occurs due to pneumonia every year, Nepalese scenario shows 42 percent of childhood diseases are due to Acute Respiratory Infections (Dixit, 2005), the second leading cause of childhood mortality.

More than 10,000 Nepali children below 5 years of age die annually due to pneumonia which has reduced significantly as compared to death tolls of 1990s from as high as of 40,000; yet the figures are still significant and substantial (WLF, 2010). This decrease in death rates can be largely attributed to improvements in treatments and antibiotics use. Nepal is one of the top seven countries in the world to cut the child mortality rate remarkably since 1990 (UNICEF, 2006). But morbidity has not shown a parallel decline. This is probably because of limited changes in behavioral factors when it comes to personal hygiene such as hand washing, low level of awareness on disease prevention and immunization against ARIs- pneumonia. The treatment gap and lack of appropriate health care are the major problems in treating pneumonia (WLF, 2010).

Researches find the worst cases of ARIs-pneumonia in the urban slums and squatter settlements (WHO, 2012; UNICEF, 2006). In these settlements overcrowding leading to congestion and poor basic amenities coupled with inadequate attention to personal hygiene result in a greater risk of infection. Worse water quality, poor housing and infrastructure, congestion, air pollution are among the causes of incidences of ARIpneumonia in the squatter settlements. Literatures find that the economic costs and burden of pneumonia prevalence is more than the medical cost of treating the disease, and the opportunity cost of care-takers has significant proportion on total cost to the dwellers. Non-medical costs, home treatment costs and other indirect costs to the households should be considered due to childhood diseases (Alam, 2009).

Small children inhale more pollutants per pound of bodyweight as compared to adults because of their greater respiratory rates. Also, children in squatter settlements spend more time engaged in various activities than adults and other children outside. In addition, because of young children's height and play habits, they are more likely to be exposed to pollutants or aerosols that are heavier than air.

Acute respiratory infections are recognized as the major childhood problems underage of five in Nepal by the ministry of health (MoHP, 2011). Demographic health survey assesses more than 7 percent of the children in country with age group $6-23$ months have been affected by ARIs which is accounted as most vulnerable age group. The children in hilly region and the children living in Western, Mid Western or Far 
western regions are attacked almost two times more by ARIs than children in other places of the country (MoHP et al, 2012). In Nepal, children from lower and highest wealth quintile families are found suffering from less ARIs attacks than children from middle wealth quintile families (MoHP, 2012).

The economic costs of illness are direct costs as well as indirect costs to the parents such as productivity loss, absenteeism from work places, income foregone of caretakers and home treatment costs. However, the financial cost does not include related direct costs and indirect costs (Kunaluck, 1996). Another type of cost of childhood ARIs is associated with household's attempts to averting activities. This study analyzes household costs due to child ARI to the dwellers and computes the DALYs for underfive children suffered from ARIs in the squatter settlements of Kathmandu valley.

\section{REVIEW OF LITERATURE}

Empirical studies at the national level to determine the socio-economic variables and risk factors of ARIs are still lacking. Most of the studies focus on the financial and direct cost of the diseases that ignore the indirect costs, the overall health outcome and the burden of diseases. Very few studies try to compute the economic cost of illness. The main problem behind this is lack of sufficient and reliable data and less priority given in health researches by the society and the concerned people.

\section{Risk Factors of Child ARIs}

A large number of risk factors of ARIs are identified and major causes of ARIs and pneumonia have been found significant in various studies. WLF (2010) outlines the major risk factors, household behavior, DALYs lost and environmental factors related to ARIs barriers to exclusive breastfeeding such as time constraints, cultural norms, multiple births, various indoor and outdoor pollutions particularly passive smoking, inadequacy by of ventilation, type of cooking fuel, overcrowding, poor housing structures, number of siblings, and poor sanitation as the major risk factors of child ARIs.

In a case control study in Sao Paulo Cardoso et al. (2004) found crowding ( $>4$ people sharing the child's bed room) to be associated with 2.5 fold increased risk of ALRIs. In their study Brims et al. (2005) found the strong evidences from developing countries linking solid fuel used with increased incidence and severity of child ARIs less than five years. A focused ethnographic study conducted by USAID (2005) explored recognition and interpretation of child ARIs signs and symptoms and management by households in the four Terai districts of Nepal. Most mothers of the children believed that child ARIs are seasonal and not considered to have the serious impacts. Mothers 
of high income and educated family were more conscious and relatively quick approaching the health care providers as compared to mothers from relatively poor and illiterate family. The mother's socio-economic status, education level and income have contributed over child ARIs. The household's behavioral factors like smoking, less practice of hand washing and teeth brushing, multiple sex partners of mothers etc. are also found significant to increase child ARIs (Mishra et al., 2005).

\section{Cost}

The economic cost of a disease can be associated with averting and mitigating activities to the households. The indirect cost is broadly decomposed in two components: lost work hours and productivity lost. Jung (2009) measured a variety of direct and indirect cost of illness at national level in South Korea. Direct cost includes medical expenses for both outpatient and inpatient treatments, transportation cost and care giver's cost while indirect cost covers foregone earnings from lost work days due to illness and loss of earnings due to premature death. The study used human capital approach to estimate the indirect cost. The total cost was KRW 56.06 trillion amounting 6.28 percent of the GDP. In a study of household cost due to childhood diarrhea conducted at the slum area of Dhaka, Bangladesh, Alam (2009) estimates direct cost of home treatment, medical treatment and transportation cost. The opportunity cost of time spent by the care giver of sick child has been estimated by providing different weights for the work hours lost for the caregivers at night, morning and day time as well as the weights was different for unemployed. Various studies computed direct cost of child pneumonia for hospitalized children. Hussain et al (2008) and Saraf (2005) determined the cost of pneumonia to severely affected children in their separate studies. They estimated total direct cost from very limited cost components like cost of consultation, medicine, diagnostic tests, meals and transportation costs. The direct-indirect cost composition was 72.2 percent and 27.78 percent respectively in Saraf's study for the hospitalized children in Kanti Bal Hospital, Kathmandu, Nepal. Adhikari et al (2002) estimated more costs components for the households due to Japanese Encephalitis. The indirect costs were decomposed as time lost after the symptoms of disease before treatment; time lost during treatments and restricted work days. Total DALYs lost was 493.92, and share of male was higher (58 percent) than female.

Murray (1994) developed a scale to provide different weights that standardized the score of ability to perform certain function and duration of disease. The key point DALY makes is that any social variables such as income or geographical origin do not affect the outcome in order to maintain the equity in measures. Fox-Rushby and Hanson (2001) provide more specific methodology and formula to calculate DALYs for cost effectiveness analysis. They have been using DALYs as an outcome indicator in microeconomic evaluations as well as a sectorial prioritization exercise for cost 
effectiveness analysis. DALYs due to ARIs in two similar cross sectional studies at Sindhupalchowk district and Dhading district of Nepal are significantly different. Pathak (2010) collected the cross sectional data during January to March and estimated about 336 DALYs lost due to ARIs. And, Dhimal et al. (2010) collected the household data about ARIs from October to January and found total 1284 DALYs were lost due to ARIpneumonia. However, the DALYs differ for large and small size of sample households. Both the studies estimate that about 50 percent of DALYs were attributed to the indoor smokes.

\section{METHODOLOGY AND DATA}

The economic model used to describe health outcomes and its association with technical and socio-economic conditions is evidenced on epidemiology literature (Hart et al, 2002). In such studies, Household's behavior is modeled using a health production function in which pollution variable (for example water or air pollution) is considered as a factor in the production of health. Also, this study models household behavior to minimize a specific health end point: morbidity effects of pollution on children with ARIs (defined as symptoms including coughing, wheezing, and /or shortness of breath). Following the standard household model (Freeman, 1993), the health outcome is a function of pollution exposure and the mitigating and averting behavior of the household.

This study estimates the household cost due to childhood ARI incidence based on Prevalence approach following attributable cost measurement of Cost of Illness (COI) methodology prescribed by Rice (1967). Most COI studies distinguish between direct costs and indirect costs. Direct costs measure the resources used to treat illness while indirect costs measure the loss of productivity. COI methodology estimates the disease attributable costs that could be avoided if a case of the disease were prevented (Dadidone \& Street, 2011) and attributable costs are estimated by multiplying the incidences cases by the aggregate cost of each condition and summing across all conditions. In order to estimate the cost of childhood ARIs, only the households which had a child suffered from ARIs during the recall period are included.

The data were collected by conducting a household survey during March to April, 2012 from 15 squatter settlements. The sample size has been computed using simple random sampling formula that comes to be 115 from the population. Taking into account the demographic and socio-economic differences among the squatter settlements and density of under-five children, KMC-29, KMC-3, KMC-32, KMC-6, KMC-16, Manohara Squatter settlement and Mahankal VDC were selected in the first 
stage. The population distribution, household number and respective sample size is given in the Table 1.

Table 1: Distribution of Sample Households in the Study Area

\begin{tabular}{llcccc}
\hline SN & \multicolumn{1}{c}{$\begin{array}{c}\text { Name of Squatter } \\
\text { Settlement }\end{array}$} & Location & $\begin{array}{c}\text { Total Number } \\
\text { of Households }\end{array}$ & $\begin{array}{c}\text { Total } \\
\text { Population }\end{array}$ & $\begin{array}{c}\text { Sample } \\
\text { Size }\end{array}$ \\
\hline 1 & Dhikure Chauki & KMC-29 & 27 & 116 & 2 \\
2 & Ranibari & KMC-29 & 45 & 81 & 3 \\
3 & Sangamtole & KMC-29 & 34 & 212 & 3 \\
4 & Narayan Tole & KMC-3 & 29 & 123 & 2 \\
5 & Khadipakha & KMC-3 & 152 & 862 & 11 \\
6 & Pathivara & KMC-3 & 174 & 732 & 12 \\
7 & Devinagar & KMC-32 & 64 & 242 & 4 \\
8 & Shanti Binayak & KMC-32 & 42 & 163 & 3 \\
9 & Subigaun & KMC-6 & 40 & 226 & 3 \\
10 & Ramhiti & KMC-6 & 129 & 668 & 9 \\
11 & Buddhajyoti Marga & KMC-16 & 74 & 355 & 5 \\
12 & Balaju Jagriti Tole & KMC-16 & 148 & 780 & 10 \\
13 & Manohara & Bhaktapur & 589 & 2422 & 41 \\
14 & Golfutar & Mahankal VDC & 26 & 146 & 2 \\
15 & Mandikhatar & Mahankal VDC & 79 & 368 & 5 \\
& & & 1652 & 7496 & 115 \\
\hline
\end{tabular}

Source: DUDBC, 2010

For the purpose of arriving at a representative sample, the stratified sampling technique is used and the basis for stratification is the proportion of households in the squatter settlements. The selected sample area consisted a total of 1652 households $(60 \%)$ and 487 (56\%) under five children living in the squatter settlements.

\section{Direct Economic Costs to the Households}

Direct costs are the costs associated with prevention or treatment of ARI-pneumonia. The direct costs are sub-divided into two types: a) Core Direct Costs: This includes formal payments for care such as hospitalization, outpatient service, physician service, home care and other medical non-durable costs. b) Related Direct Costs: expenditure on transportation for health care facility, extra food and meals costs due to illness and certain household expenditures such as special diets and clothing, relocation and expenses on keeping child warm are included in related direct costs. 


\section{Indirect Economic Cost}

Indirect costs include loss of productivity and resources due to morbidity and mortality, which inherently places a monetary value of life (Russel, 2004). The cost of lost work time/or leisure-time is the opportunity cost of the person taking care of the child during illness. This study uses the Human Capital Approach, among various methods, to estimate indirect costs. In this approach, the total indirect cost is decomposed to the Loss of Earnings Due to Premature Death and Loss from Lost Workdays. The study uses the total monthly wage by age and gender and the total life-time income of a person by age group and gender. Also, the rate of participation in economic activities and employment rate are taken into the calculation because not all household members participate in economic activities. Finally, the number of death by disease is multiplied to the life-time expected income by each age group and gender. The equation that is used to calculate the loss of earnings as the opportunity cost of premature death is simply the modified version of Jung (2009) which is :

$$
\text { Lost earnings due to premature death }=\sum_{j} \sum_{i}\left\{F_{i j} \frac{Y_{j}^{t-\tau} \times P_{i j} \times e_{i j}}{(1+r)^{i}}\right\}
$$

Where, $\mathrm{i}=$ Expected age, $\mathrm{t}=$ Age at death, $\mathrm{j}=$ Gender $(1=$ male, $2=$ female), $\tau=$ Number of expected productive years, $\mathrm{F}_{\mathrm{ij}}=$ Number of deaths during study period, $\mathrm{Y}_{\mathrm{j}}=$ Annual expected income, $\mathrm{P}_{\mathrm{ij}}=$ Participation rate in economic activities , $\mathrm{e}_{\mathrm{ij}}=$ Employment rate, $\mathrm{r}=$ Discount rate

To estimate the loss from lost workdays, only economic valuation of care taker's income lost is computed as the sick children are assumed to have not involved in economic activities.

The opportunity cost to the care-giver is computed by multiplying the total hours of work time and leisure time spent nourishing the affected child and the wage rate of the care giver in case of an earning member. In case of non earning care givers, the average hourly income of the family is used (Alam, 2009). As the opportunity cost of care givers is not same for each hours of time lost in a day, different weights are assigned: 1 for hours lost at daytime, 0.5 for hours lost in morning and evening and 0 for hours lost at night. Averting costs include the costs related to the activities undertaken to avoid the incidence of ARIs such as use of masks, handkerchief, purchase of special clothes to keep child warm, immunization/vaccination purchase of home care medicines and special diets before ARIs attacks. Mitigating costs include costs borne by households after ARIs attacks: hospital and home care costs, food, meals diet and vitamin costs, follow up costs, transportation cost and productivity losses of care takers. 


\section{Computation of DALYs}

The burden of ARI-pneumonia due to illness is calculated in terms of DALYs lost using the WHO-Burden of Disease Series. DALY is a combined measure of years in disability and years of life lost due to premature death from disability (Lima, 2005). Two mathematical equations are used to calculate DALY, years of life lost (YLL) and years lived with disability (YLD). YLL is the number of years of life lost due to premature death. YLD is the number of healthy years lost due to disability from the condition until remission or death. The DALY scale (weight) 1 indicates death and 0 shows perfect health. To calculate YLL and YLD for a wide range of diseases and injuries, secondary data are used rather than a tool developed for primary data collection (Cairns \& Julia, 2005). However, this study follows the formula of Small-Area Analysis of DisabilityAdjusted Life Years (Lima, 2005) to calculate DALY score.

$$
\mathrm{DALY}=\mathrm{YLL}+\mathrm{YLD}
$$

where,

YLL = Years of life lost due to death (mortality component of DALY)

$$
\text { and, } \mathrm{YLL}=\mathrm{N} \times \frac{1-\mathrm{e}^{-\mathrm{rLE}}}{\mathrm{r}}
$$

$\mathrm{N}=$ Number of deaths due to ARIs in under five children, LE = Standard Life Expectancy at death, $\mathrm{r}=$ Discount rate.

YLD = Years of life lived due to disability (morbidity component of DALY)

$$
\text { and, } \mathrm{YLD}=\mathrm{IR} \times \mathrm{DW} \times \frac{1-\mathrm{e}^{-\mathrm{rLE}}}{\mathrm{r}}
$$

IR = Incidence rate of ARI in under five children, DW = Disability weight, Le = Length/duration of illness in children.

The disability weight of life (DW) below the age of 9 is less than 1 (Barendregt et al, 1996) and is computed following the general formula proposed by Murray (1994) to weight life years by age:

$$
\mathrm{DW}=\mathrm{Cxe}-\beta \mathrm{x}
$$

where, $C$ is the age weighting correction constant, $\beta$ is the parameter from the age weighting function, $x$ is age and $\mathrm{e}$ is the mathematical exponential. In the specific forms used for calculating DALYs, C equals 0.16243 and $\beta$ equals 0.04 (Murray, 1994). 


\section{RESULTS AND DISCUSSION}

\section{Summary Statistics of Households and Individual Characteristics}

Table 2 presents the summary statistics of the sampled households. On an average, 5 people live in one living structure with minimum 2 to maximum 11 household members which comes to be 1.17 household members higher than the combined household size in Kathmandu. 34 percent houses are of permanent types and about 30 percent are found temporary structures made from bamboo, plastic, tripal, khar, mud and mandro in roof and wall. The average number of floors used is 1.27, but 75.65 percent livuresing struct have only one floor. 62.61 percent households cook food inside the same room that they use it together as bed- room for child. And only 37.39 percent have separated bed room from kitchen. In 65.22 percent households, at least one person is smoker.

Table 2: Household and Individual Characteristics

\begin{tabular}{lccccc}
\hline Variable & Obs. & Mean & Std. deviation & Min & Max \\
\hline Electricity use & 115 & 0.965 & 0.184 & 0 & 1 \\
L-P gas use & 115 & 0.948 & 0.223 & 0 & 1 \\
No. of rooms & 115 & 2.147 & 1.194 & 1 & 6 \\
No. of floors & 115 & 1.278 & 0.522 & 1 & 3 \\
Ownership TV & 115 & 0.835 & 0.373 & 0 & 1 \\
Ownership radio & 115 & 0.522 & 0.502 & 0 & 1 \\
Ownership refrigerator & 115 & 0.104 & 0.307 & 0 & 1 \\
Ownership cycle & 115 & 0.287 & 0.454 & 0 & 1 \\
Ownership thermos & 115 & 0.635 & 0.483 & 0 & 1 \\
Ownership heater & 115 & 0.252 & 0.436 & 0 & 1 \\
Ownership mobile/ phone & 115 & 0.957 & 0.205 & 0 & 1 \\
Average number of children & 115 & 2.12 & 1.04 & 1 & 5 \\
Age of (mothers) in years & 115 & 28.62 & 6.92 & 18 & 50 \\
Income of (mothers) in Rs. & 84 & 4419.05 & 2667.49 & 1000 & 16000 \\
Hours spent on child care (mothers) & 112 & 3.27 & 1.81 & 1 & 10 \\
Bottle feeding practice & 115 & 0.39 & 0.49 & 0 & 1 \\
Measles vaccination & 115 & 0.8 & 0.41 & 0 & 1 \\
Age (child) & 115 & 2.71 & 1.37 & 1 & 5 \\
Play hours (child) & 112 & 3.57 & 2.03 & 1 & 8 \\
Hand washing practice & 115 & 0.67 & 0.48 & 0 & 1 \\
Prevalence of ARIs & 115 & 5.07 & 2.87 & 1 & 12 \\
\hline
\end{tabular}

Source: Household survey, 2012 
The major source of cooking fuel is LP-gas in the squatter settlements (95\%). About 84 percent households possess television, 64 percent use thermos while only 25 percent have heater. Average mother's age and monthly income are 28.62 years and Rs. 4419.50 who spend only 3 hours and 16 minutes daily in child care. On an average, the children's daily play hours are about half hour longer than mother's daily hours spent with children. The average age of under-five children is 2.71 years and these children suffer from 5 episodes of ARIs on an average during a year.

Among the total households having affected their children with ARIs and having 22.73 percent tried for home treatments of which 35 percent were recovered, 30 percent rushed to local health posts or private clinics and remaining 35 percent went to the traditional healers'.

Table 3: Treatment Places

\begin{tabular}{lccccc}
\hline & $\begin{array}{c}\text { Home } \\
\text { treatment } \\
\text { (Percent) }\end{array}$ & $\begin{array}{c}\text { Local } \\
\text { Health post } \\
\text { (Percent) }\end{array}$ & $\begin{array}{c}\text { Private } \\
\text { clinic } \\
\text { (Percent) }\end{array}$ & $\begin{array}{c}\text { Hospital } \\
\text { (Percent) }\end{array}$ & $\begin{array}{c}\text { Traditional } \\
\text { Healers } \\
\text { (Percent) }\end{array}$ \\
\hline Home treatment (Percent) & 22.73 & 25.00 & 5.00 & 0.00 & 35.00 \\
Local Health post (Percent) & 18.52 & 30.69 & 7.41 & 14.81 & 40.74 \\
Private clinic (Percent) & 2.86 & 5.71 & 39.77 & 8.57 & 28.57 \\
Hospital (Percent) & 0 & 19.05 & 14.29 & 23.86 & 61.91 \\
Traditional Healers (Percent) & 20.59 & 32.35 & 29.41 & 38.24 & 38.64 \\
\hline
\end{tabular}

Source: Authors' computation from Field Survey data, 2012

Table 3 reflects that most of the affected children were either taken to private clinic (39.77 percent) or at local health posts (30.69 percent), and large number of children treated in these places was taken to traditional healers' too: 28.57 percent and 40.47 respectively. The children who were treated at hospital are taken to local health posts or at private clinic before and 61.91 percent children treated at hospital were taken to traditional healers'. This shows more serious the case, households visit more frequently to traditional healers'. During the six months period, four children were hospitalized in the squatter settlements due to pneumonia and severe pneumonia followed by fever. The choice of treatment place is found to be affected by the distance from house and severity of disease.

71.41 percent of the affected children were taken to health care providers' or at hospital of which 84.06 percent were recovered with first or second visits and 15.94 percent needed more than two visits. 1.45 percent households have to visit five times with 
health care providers' during last six months due to child ARIs. On an average, 1.91 follow ups were observed for each case of ARIs attacks.

\section{Cost Analysis}

In order to calculate cost of child ARIs, only households which had a child suffering from respiratory infection within the recall period of six months are considered. Households incurred different types of direct costs once a child suffered from ARIs attack. These costs are classified into cost of treatment at home; cost of medical treatment in a hospital, private clinic or at health posts, cost of transportation and traditional healer's cost as direct cost and caregiver's income and leisure lost due to child ARIs as indirect cost.

Table 4: Composition of Various Costs Related to ARIs

\begin{tabular}{llccc}
\hline SN & Cost Items & $\begin{array}{c}\text { Per episode cost } \\
\text { (in Rs.) }\end{array}$ & Percent & $\begin{array}{c}\text { Per patient } \\
\text { cost (in Rs) }\end{array}$ \\
\hline 1 & Home treatment cost & 1980.00 & 0.13 & 99.00 \\
2 & Private clinic treatment cost & 20335.00 & 1.37 & 333.36 \\
3 & Hospital treatment cost & 35585.40 & 2.40 & 1779.27 \\
4 & Total transportation cost & 5490.00 & 0.37 & 91.50 \\
5 & Extra food purchase cost & 4440.00 & 0.31 & 158.57 \\
6 & Traditional healer's cost & 2965.00 & 0.21 & 87.21 \\
7 & Total direct cost (1+2+3+4+5+6) & 70795.40 & 4.77 & 2548.91 \\
8 & Averting costs & 43945.00 & 2.96 & 382.13 \\
9 & Earnings loss due to premature death & 1353309.00 & 91.21 & 1353309.00 \\
10 & Loss of lost workdays & 15718.92 & 1.06 & 365.56 \\
11 & Total indirect cost (9+10) & 1369027.92 & 92.27 & 31114.27 \\
12 & Total cost (7+8+11) & 1483768.32 & 100 & 32300.89 \\
\hline
\end{tabular}

Source: Authors' computation from Field Survey data, 2012

Among the various costs related to child attacks of respiratory diseases to the households, indirect cost has largest share: 92.27 percent, this is because of the large proportion of cost of lost earning due to premature death. When this component is dropped from the analysis, total indirect cost reduces to 12.04 percent of the total cost. However, in amount, this comes to be near to the share of private clinic treatment cost. Very insignificant portion ( 3 percent) of the total amount is covered by the purchases for children that reduce the potential risk of ARIs. The composition of direct cost is 3 percent, 29 percent, 50 percent, 8 percent, 6 percent and 4 percent on home treatment, clinic treatment, hospital treatment, on transportation, on extra food purchase and for 
traditional healers respectively when indirect cost due to premature death is dropped. This composition exhibits that households are ready to spend a significant amount for treatment at hospital and private clinic after diseases attacks but are less likely to spend to avoid diseases at home. The per patient direct cost is obtained by dividing the total cost for each items by the total number of ARIs- suffered children seeking treatment at respective places. This shows the largest share of hospital treatment cost followed by private clinic treatment cost and extra food purchase costs. Per child indirect cost is obtained by dividing the total indirect cost items by the number of households associated losing work hours and the total indirect cost due to premature death is related with only one household.

While comparing per episode cost and per patient cost, the total indirect cost seems significantly higher; however, when we drop the total indirect cost due to premature death from our analysis, average indirect cost components are always lower than direct cost Rs. 365.56 and Rs. 2548.91respectively.

As indicated in literature review, few studies have been found taking into account the opportunity cost due to premature death and lost work hours. Jung (2009) found 82 percent of total cost covered by indirect cost, 63 percent indirect cost covered by premature death and 4 percent of direct cost was transportation cost, which come to be consistent with findings of this study. However, Hussain et al (2008) found per episode societal cost ranging between $\$ 20.50$ and \$ 137.62 in similar type of study in Pakistan and Saraf (2005) found Rs. 5279 as average cost for households with hospitalized children. This variation in direct cost is due to the fact that unlike in this study, their studies were based on hospitalized children only. If the total cost is taken into account, the current study estimates the similar per episode cost to the households.

\section{Analysis of Direct Costs}

Direct cost related to childhood ARIs and ARIs related diseases in terms of home treatment costs, local health post and clinic treatment cost, hospital treatment cost, transportation cost, extra foods purchasing cost, payment to traditional healers and two way transportation cost comes to be Rs. 70795.40 per episode for the households that is 4.77 percent of the total cost.

Home treatment cost includes the cost of medicine bought from local store, cost of herbal medicine used such as 'Bojho', 'Honey', 'Rudilo', 'Sutho' etc and cost of homemade syrups such as lemon and hot water, boiled water, tulsi-haldi water and other syrup bought from local stores. Total of 20 households have treated their children affected by respiratory infection at home and total expense was accounted Rs. 1980 
with per episode cost of Rs. 23.02. The largest amount was observed in purchasing herbal medicine.

The average cost for the households who went to private clinics or local health posts for treatment is Rs. 333.36 with minimum Rs. 100 to maximum Rs. 2000. This cost includes doctor's fee, medicine cost and purchase of vitamins prescribed. Cost of treating at hospital is sub divided into three components: diagnostic test cost, hospital care cost and doctor's fee. Though highest share is for the cost of the diagnostic test Rs. 19733.34, the average cost is highest for hospitalized children for hospital care: Rs. 3083.33.

Total transport cost is the total amount paid by parents for two way uses of vehicles on various visits for the last episode of ARIs-attack to their children. Total transport cost is attributed to 60 cases using some types of vehicles; however, the same household had been paying both transport costs to visit hospital and clinic or local health care center.

The total transportation cost related to childhood ARIs at the last episode of diseases attacks amounts Rs. 5490 during the six months. Average transport cost for hospital visits is Rs.175.24 with standard deviation Rs. 226.99. Such variation is due to frequent visits of parents and relatives for hospitalized children but less frequent visits for follow up patients. On the other hands, total transport cost for households visits at clinic or local health care providers' is Rs. 1985 for 40 households with average Rs. 49.63 which is significantly lower than average cost for hospitalized children.

Extra food expanses involves the cost of food items, fruits, milk, tea, snacks and soup purchased for the parents or caretakers that is to be incurred only due to childhood ARIs attacks basically for the hospitalized children in this study. The total households number associated extra food cost is 28 with average cost of Rs. 158.57 and total amount of extra foods purchasing cost is Rs. 4440.

The traditional healer's treatment cost includes the total cost by the households of sick children during the visits of traditional healers, rituals, lama, jharphukgarne, heraune etc paid for their treatments, fee with two-way transportation. However, this study does not decompose the cost items. Total of 34 households visited traditional healers when their children fell sick due to ARIs before or after health care provider's visits. Cases were recovered and total cost accounts Rs. 2965 for all the visitors which account 7 percent of the total averting cost of childhood ARIs. The average cost is Rs. 87.20 per visit with minimum Rs. 10 to maximum Rs. 300. 
Though the purchase and use of various items for children can have multiple objectives , this study considers the cost related to purchasing masks, handkerchief, jacket/ sweater, warm shoes, massage oil, warm under wears and gloves as the averting activities to ARIs. The total averting cost of purchasing these items for all survey households during the recall period is Rs. 43945 which is about 40 percent lower than the total treatment cost for the affected children.

\section{Analysis of Indirect Costs}

In order to estimate indirect costs related to ARIs and ARIs related diseases, the Human Capital Approach according to Cost of Illness Study is used following Jung (2009).

\section{Loss of Earnings Due to Premature Death}

We adopted the gross loss output approach which estimates the earnings by replacing it with lost income due to disease. As only one death was observed during six month period, this study employs data on age at death ( $\mathrm{t}), 2$ years. It is assumed that no productive activities are executed in two age groups: 0-16 and over 70 years. A 3 percent discount rate is applied to convert the future income to present value following Global Burden of Disease Study (WB, 1993). The total monthly income for mothers is employed to compute the annual average expected income because dead child was female. Rate of participation in economic activities is simply the ratio of women participation in income earning activities in the squatter settlements which is computed 0.6783. To have the expected productive life and employment rate, secondary data is imported from CBS (2010), MoHP (2011) and World Bank(2012) country figure-2012. The life expectancy for women in Nepal is used 69.22 years $(\mathrm{WB}, 2012)$ and women employment rate is 0.75 (MoHP, 2012). This way, the expected future income from labor assuming that one lives up to life expectancy is computed Rs.13, 53,309.11in present value.

\section{Loss of Lost Workdays}

The loss from lost workday during the medical treatment is equivalent to the patient's lost workdays and caretaker's lost days due to non fatal diseases (EPA, 2010). Since under-five children are not involved in any kind of productive activities, patient's lost workday cost is discarded in this study.

The cost of lost work time and/or leisure time is the opportunity cost of the person taking care of the child during illness. This study computes the opportunity cost to the care giver by multiplying the total hours of work-time and leisure-time spent nourishing the affected child and the wage rate of the care-giver in case of an earning member. In case of non-earning members, the average hourly income of mothers (Rs. 
18.41) is used. This gives the total cost Rs. 15718.92 for an average squatter household in Kathmandu which further decomposed comes to be attributed to Rs. 4694.59, Rs. 9242.6 and Rs.1718.73 as monetary value of lost work hours in the morning, daytime and evening to the households.

\section{Health Outcome and Burden of ARIs}

Health outcome of any disease is measured in terms of healthy lives lived during the disease (i.e. QALY) and loss of healthy life due to premature death and disability or injury (DALY). One year of DALY is one lost year of healthy life it captures in a single indicator the impact of both premature death and non fatal health outcomes of diseases and injuries. The assumption made in computing DALYs in this study is that the average duration of respiratory infection is same for each episode. The DALYs estimated using the prescribed methodology for one year is 70.87 for under-five children living in the squatter settlements.This exhibits on an average 70.87 years of healthy lives are lost per year either from morbidity or mortality caused by respiratory diseases for under five children. When we divide total cost for avoiding or treating the disease by the DALY score, it gives Rs.20936.48 per DALY which states that to avert the occurrence of one year of unhealthy or disabled life of under-five children due to ARIs, a household should make Rs. 20936.48 expenses on child's treatment and averting activities.

When the total DALY is decomposed into YLL and YLD, the composition shows that 41.13 percent DALY is attributed to premature death component (YLL) and 58.87 percent of DALY occurred due to non-fatal type of respiratory diseases (YLD). Further, to compare the relative contribution of YLD and YLL to DALY total, the percentage contribution of non-fatal burden to the fatal burden (YLD/YLL) is computed; this ratio of 1.43 shows about one and half times higher burden of child ARIs accounts for the non-fatal types of respiratory infections. As ARIs are generally temporary and non fatal diseases, a simple assumption can be made that the loss of quality of life determined by ARIs in QALY calculation is exactly equivalent to the level of disability estimation to DALY calculation i.e. $\mathrm{QW}=1-\mathrm{DW}$, where $\mathrm{QW}$ is the quality of life weight (Sassi, 2006).

Therefore, QALYs lived while affected by ARIs = IR X (1-DW) $X \frac{1-e^{-f L e}}{r}$

The per year total QALYs gained by under-five children living in the squatter settlements is 100.05 years due to household's attempts of averting and mitigating ARIs. 
On an average, boys lost 0.45 years or nearly half year of DALY and DALY lost by girls is one and a quarter year of life. However YLD among boys and girls does not vary by a large number. The non-fatal component of disability (YLD) for girls is about 10 percent higher than that of boys. This implies that both DALY and YLD are higher for girls and ARIs affected girls are living about four years higher with disability than boys. If we drop the YLL from our analysis (the maximum DALYs 31.50 is deducted from total DALY) the total DALYs lost by two years age group is still highest compared to other age groups (23.67). This signifies that the burden of ARIs is highest during the second year of birth.

When child passes his/her third and fourth year, the burden of disease is observed declining both in total and on average too. Though the cases of Severe Pneumonia is very low, it seems as the major cause of DALYs lost in the squatter settlements contributing more than fifty percent of total DALYs which is highly influenced by the YLL factor. The cases of Pneumonia and No Pneumonia (cold and cough) caused 23.24 percent and 23.38 percent of total burden respectively.

\section{CONCLUSION}

The incidences of child ARIs is 5.1 episodes per year which is more than two times higher in squatter settlements than that for whole country contributing 70.87 DALYs lost yearly. 92.35 percent of the total cost is attributed to indirect cost due to premature death and productivity lost. About 80 percent of the direct cost is made on medical treatment and only 3 percent of total cost is found expended by households for averting activities before disease attacks and 97 percent of total cost is associated with mitigating attempts. The DALY score is attributed to 45 percent to boys and 55 percent to girls and for the two years age group, highest share of DALYs is lost (77.85 percent). Households can minimize total cost and the burden of disease by increasing expenses on averting activities of childhood diseases such as purchase of nutritious foods, fruits, vitamins, warm clothes, improving housing structures and following pre-attack cautions in their daily activities.

\section{References}

Adhikari, S. R. \& Sharma, B.P. (2002). A study on socio- economic determinants and economic burden of Japanese Encephalitics in Kailali District of Nepal. Kathmandu: Nepal Health Research Council.

Alam, M. J. (2009).Prevalence and costs of childhood diarrohea in the slums of Dhaka. South Asian Network for Development and Environment Economics (Working Paper No 46-09). 
Barendregt, J. J., Bonneux, C. \& Maas, P.J. V. (1996). DALYs: The age weights on balance. Bulletin of WHO, 74, 439-443.

Brims, F. \& Chauhan, A.J. (2005). Air quality, tobacco smoke, urban crowding and day care: Modern menaces and their effects on health. The Pediatric Infectious Disease Journal, 24(11), S152-S158.

Cairns, J. \& Julia, F.R. (2005). Economic evaluation. New Delhi: McGraw Hill.

Cardoso, M. R., Cousens, S. N., Squeira, L. F. G., Alves, F. M., \& D' Angelo, L.A. (2004). Crowding: Risk factor or protective factor for lower respiratory disease in developing countries, BMC Public Health, 3(1), 173-178.

CBS.(2010).Nepal living standard survey. Kathmandu: Government of Nepal.

Dadidone, S. \& Street, A. (2011). Estimating the costs of specialized care. Centre for Health Economics: The University of York.

Dhimal, M., Dhakal, P., Shrestha, N., Baral, K., \& Maskey, M. (2010).Environmental burden of Acute respiratory infection and pneumonia due to indoor smoke in Dhading, JNHRC, 18 (1),1-4. Ministry of Health, Government of Nepal.

Dixit, H. (2005).Nepal's quest for health (3rd ed.). Kathmandu: Education Publishing House.

EPA. (2010).The benefit and costs of the Clean Air Act 1990 to 2010. United States Environment Protection Agency. EPA-410-R-99-001.

Fox-Rushby, J. \& Hanson, K. (2001). How to do (or not to do)... Calculating and Presenting disability adjusted life years (DALYS) in Cost Effectiveness Analysis. Oxford University Press. Health Policy and Planning 16(3), 326-331.

Freeman, A.M. (1993). The measurement of environmental and resource values. Washington, DC: Resource for the future.

Hart, C. A., Beeching, N.U. \& Duerden, B.I. (2002).Respiratory infection. Journal of Medical Microbiology, 51(11), 903-94.

Hussain, H., Waters, H., Khan, A.J., Omer, S. B. \& Halsey, M.A.(2008).Economic analysis of childhood Pneumonia in Northern Pakistan. UK: Health Policy and Planning.

Jung, Y. H. (2009). The socio-economic cost of illness in Korea. Seoul: Korean Institute for Health and social Affairs.

Kunaluck, K. (1996). Economic loss assessment of lung cancer caused by smoking. Bangkok: Thammasat.

Lima, V. D. (2005). Small area disability-adjusted life years: A new approach to the spatiotemporal analysis of public health surveillance data. A PhD dissertation. The University of British Columbia. 
Mishra, V., Smith, K.R., \& Rutherford, R.D. (2005). Effects of cooking smoke and environmental tobacco smoke on acute respiratory infections in young Indian Children. Journal of Population and Environment, 26, 375-396.

MoHP.(2011).Nepal demographic and health survey, preliminary report. Kathmandu: Population Division Ministry of Health and Population of Nepal.

MoHP.(2012).Nepal demographic and health survey 2011. Kathmandu: Ministry of Health and Population of Nepal.

MHoP [Nepal], New ERA, \& ICF International Inc. (2012). Nepal demographic and health survey 2011. Kathmandu, Nepal: Ministry of Health and Population, New ERA, and ICF International, Calverton, Maryland.

Murray, C. J. L. (1994). Quantifying the burden of diseases, Bulletin of World Health Organization, 72, 429-445.

Pathak, R. P. (2010). An assessment of the disease burden of acute lower respiratory infection among under five children due to Indoor air pollution in Sindupalchowk district Nepal. Kathmandu: Nepal Health Research Council.

Rice, P. D. (1967). Estimating to cost of illness. New York: McMillan.

Russel, S. (2004). The economic burden of illness for households in developing countries: A review of studies focusing on malaria, tuberculosis, and human immunodeficiency virus/acquired immunodeficiency syndrome. The American Journal of Tropical Medicine and Hygiene, 71(2), 147-155.

Saraf, A. (2005). Economic impact of air pollution in Kathmandu Valley: An assessment of cost of morbidity in Children. An unpublished Master's Thesis, Tribhuvan University.

Sassi, F. (2006). Calculating QALYs, comparing QALY and DALY calculation. Oxford Journal of Medicine, Health Policy and Planning, 21, 402-408.

UNICEF/WHO.(2006).Pneumonia: The forgotten killer of children. Retrieved from .

USAID. (2005). Focused ethnographic study on acute respiratory infection among children. Solution Consultant (P) LTD.

WHO. (2011).World health statistics. Switzerland: World Health Organization.

WHO. (2012). Documents on acute respiratory infections/pneumonia. Geneva.

WLF (2010). Acute respiratory infections Atlas. New York: World Lung Foundation.

World Bank (WB) (1993).World development report: Investing in health. New York: Oxford University Press.

World Bank.(2012). Life expectancy at birth, total (years). Washington, DC: The World Bank Group. 